\title{
Relationships between the Reduced Glutathione (GSH) Reactivity of Dental Methacrylates, Michael-reaction Acceptors and their ${ }^{13}$ C-NMR Chemical Shift of $\beta$-Carbons
}

\author{
Seiichiro Fujisawa \\ Meikai University School of Dentistry, Saitama-ken, Japan
}

Corresponding author: Seiichiro Fujisawa, Meikai University School of Dentistry, 1-1 Keyakidai, Sakado, Saitama-ken, 350-0283, Japan, Tel: +81-492-86-1712; E-mail: fujisawa33@nifty.com

Received date: May 23, 2017; Accepted date: June 07, 2017; Published date: June 15, 2017

Copyright: (C) 2017 Fujisawa S. This is an open-access article distributed under the terms of the creative Commons Attribution License, which permits unrestricted use, distribution and reproduction in any medium, provided the original author and source are credited.

Citation: Fujisawa S. Relationships between the Reduced Glutathione (GSH) Reactivity of Dental Methacrylates, Michael-reaction Acceptors and their ${ }^{13}$ C-NMR Chemical Shift of ?]-Carbons. Periodon Prosthodon. 2017, 3:2.

\section{Abstract}

(Meth)acrylates, $\alpha, \beta$-unsaturated esters are Michaelresponse acceptors and have concentrated on antagonistic wellbeing exercises, for example, oral sicknesses and hypersensitive contact dermatitis. A connection between decreased glutathione (GSH) reactivity and lethality for (meth)acrylate monomers has been set up. To foresee the GSH reactivity of dental methacrylate monomers, the ${ }^{13} \mathrm{C}-\mathrm{NMR}$ compound movements of $\beta$-carbon $(\delta \quad C \beta)$ and the ${ }^{1} \mathrm{H}$-NMR movements of the proton joined to the $\beta$-carbon $\left(\delta H_{a}, \delta\right.$ $\mathrm{H}_{\mathrm{b}}$ ) were decided for a preparation set of acrylate and methacrylate monomers having diverse nucleophiles. Writing information for monomer GSH reactivity were utilized for expectation of the GSH reactivity of dental methacrylates. Critical direct connections between GSH reactivity $(\log K)$ and $\delta C \beta$ or $\delta \mathrm{Ha}$ were watched $(p<0.001)$. A worthy relationship for the $L_{50}$ in mice of acrylates and methacrylates was seen as far as log $K$ $\left(p<0.005\right.$, exception: HEMA). The oral mouse $L_{50}$ values for some dental dimethacrylates, two Michael-response acceptors (two-twofold bonds, two $\beta$-carbons) were assessed by direct relapse bend fitting of GSH reactivityharmfulness reaction information. The present discoveries propose that NMR spectra may be helpful for anticipating the danger of dental methacrylates.

Keywords: Dental methacrylates; GSH reactivity; NMR spectra; Structure-activity relationships

\section{Introduction}

Methacrylate monomers are generally utilized as a part of dentistry as a denture base, and as covering materials, remedial pitches and holding operators. By and large, methacrylate monomers don't polymerize totally in air since oxygen goes about as a biradical and stifles polymerization, leaving unreacted methacrylate bunches on the gum surface [1]. In this way unpolymerized methacrylates in dental materials are an essential element bringing on bothering and unfavorably susceptible responses in the oral hole [2-4]. Contingent upon the lipophilicity (octanol-water segment coefficient, $\log \mathrm{P}$ ) of monomers, they will live prevalently in the cell layers of oral tissues. Since the organic frameworks are hetrogenous conditions, the hydrophobicity of monomers influences significantly more cytotoxicity than the hydrophilicity. Notwithstanding $\log \mathrm{P}$, , -unsaturated carbonyl methacrylates utilized as tar monomers may display danger however response with tissue nucleophiles by means of Michael expansion [2-6] (Figure 1). Acrylates are notable to be substantially more electrophilic than methacrylates, and have been beforehand answered to have high danger [5-7]. Glutathione (GSH) is a nucleophile frequently utilized as a model for cell thiol gatherings. Utilization of $\mathrm{GSH}$ response rates ( $\log K$ ) has been already detailed for examinations of the quantitative structure-action connections (QSAR) of acrylates and methacrylates ((meth)acrylates), in light of the fact that their reactivity with sulfhydryl gatherings, for example, GSH and cysteine-containing polypeptides is important to their lethality $[5,6]$. Additionally, (meth)acylates with ,-unsaturated carbonyl structures have been accounted for to have allergenic properties because of their sadness of GSH [8]. In dentistry, the poisonous quality of triethyleneglycol dimethacrylate (TEGDMA) has been appeared to be identified with its reactivity with GSH [4,9], bringing about practically add up to consumption of intracellular GSH levels, transcendently through Michael option [9].

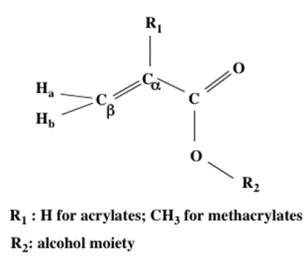

Figure 1 Chemical structure of acrylates and methacrylates. 
The reactivity of (meth)acrylate monomers ordinarily relies on upon the $\alpha$-electron thickness immediately bond, especially on the -carbon. The higher the -electron thickness of the -carbon, the higher is the attractive field where the NMR pinnacle is watched, prompting a diminishment of the NMR compound move. On this preface, it ends up plainly conceivable to connect the greatness of a NMR concoction move with the reactivity of monomers by means of responses, for example, Michael expansion [10]. Quantitative information on the GSH reactivity of $\alpha, \beta$-unsaturated carbonyl mixes, for example, acrylates and methacrylates have been accounted for $[5,7]$. Along these lines, the greatness of the NMR concoction movements of -carbons for (meth)acylate monomers might be utilized for evaluating their GSH reactivity.

We have already detailed the QSAR between the deadly oral measurements $\left(\mathrm{LD}_{50}\right)$ in mice for a progression of acrylates/ methacrylates and their NMR compound movements of $\beta$ carbons $\left(\delta C_{\beta}\right)$, or the ${ }^{1} \mathrm{H}-\mathrm{NMR}$ movements of the proton joined to the $\beta$-carbon $\left(\delta \mathrm{H}_{\mathrm{a}}, \delta \mathrm{H}_{\mathrm{b}}\right)$, showing a worthy QSAR for both descriptors [11,12]. Here, we show the QSARs (quantitative structure-movement connections) between GSH reactivity and intense poisonous quality shown by dental methacrylate monomers. The systems hidden the poisonous quality of dental methacrylates have been then examined in light of this current review's discoveries.

\section{Materials and Methods}

\section{Monomers}

The monomers utilized were methyl acrylate (MA); ethyl acrylate (EA); n-propyl acrylate (nPA); n-butyl acrylate (nBA); isobutyl acrylate (iBA); hexyl acrylate (HexylA); 2-ethylhexyl acrylate (2-ethylhexylA); methyl methacrylate (MMA); ethyl methacrylate (EMA); n-propyl methacrylate (nPMA); n-butyl methacrylate (nBMA); isobutyl methacrylate (iBMA); 2hydroxyethyl methacrylate (HEMA); benzyl methacrylate (BZMA); ethylene glycol dimethacrylate (EGDMA); triethylene glycol dimethacrylate (TEGDMA); tetraethylene glycol dimethacrylate (tetraEGDMA), and 2,2-bis [4-(2-hydroxy-3methacryloyloxy-propyloxy)phenyl]propane (bis-GMA).

\section{NMR spectra}

The ${ }^{13} \mathrm{C}-\mathrm{NMR}$ and ${ }^{1} \mathrm{H}-\mathrm{NMR}$ substance move information for different (meth)acrylates in chloroform-d $\left(\mathrm{CDCl}_{3}\right)$ [10]. Quickly, the compound movements of the showed monomers were measured in chloroform-d at $35^{\circ} \mathrm{C}$ at 125 and $500 \mathrm{MHz}$, utilizing tetramethylsilane (TMS) as an inward standard, as revealed. ${ }^{1} \mathrm{H}-\mathrm{NMR}$ compound move information for TEGDMA bis-GMA and UDMA [1]. Additionally, the ${ }^{13} \mathrm{C}-\mathrm{NMR}$ concoction movements of EGDMA, TEGDMA and bis-GMA were resolved in $\mathrm{CDCl}_{3}$ utilizing a JEOL ALPHA 500 NMR spectrometer [11-13].

\section{GSH reactivity}

Three arrangements of information for the GSH reactivity of acrylates and methacrylates under without cell conditions $[6,5,14]$.

\section{Creature testing}

$\mathrm{LD}_{50}$ information got utilizing mice intraperitoneally infused with monomers [13]. Quickly, male pale skinned person ICR mice measuring $25 \pm 5 \mathrm{~g}$ were utilized as the guinea pigs, and the $L D_{50}$ dosage for each compound was ascertained from the 7-day mortality. Information for the intense oral $\mathrm{LD}_{50}$ in male ddY mice (24-27 g) [15]. The $L D_{50}$ information for EAA [17], MMA [16], BZMA [17], AllyIMA [18], nBMA [19], TEGDMA [20] and bis-GMA [21] acquired by oral organization in rats were taken from the material security information sheets for the particular operators.

\section{Predictiong of GSH reactivity using NMR spectra}

The GSH reactivities of acrylates and methacrylates have been measured already by a few gatherings $[5,6,13]$ and the information (as log K) are abridged in Tables 1 and 2, individually. Michael expansion has been proposed as the instrument of the response of thiols with unsaturated carboxylic esters of (meth)acrylates [7], and the unsaturated $\beta$ carbon particle is the most presumably the site of assault. Spectroscopic strategies bolster synthetic advancement. NMR move investigation of the $\alpha$ and $\beta$ carbons of the twofold bond catches the quality of its Michael-tolerating capacities. On this commence, we utilized the NMR concoction move, $\delta C_{\beta}$, of (meth)acrylates as a descriptor to anticipate their $\mathrm{GSH}$ reactivity. The ${ }^{13} \mathrm{C}-\mathrm{NMR}$ substance movements of $\beta$-carbon and $\alpha$-carbon for 18 (meth)acrylates are likewise appeared in Table 1. The QSARs for distributed information of GSH reactivity as far as $\delta C_{\beta}$ or $\delta C_{\alpha}$ were explored, and the outcomes are appeared in Equations 1-5 (Table 4).

Table $1{ }^{13} \mathrm{C}$-NMR chemical shifts of beta carbon $\left(\delta C_{\beta}\right)$, alpha carbon $\left(\delta C_{\alpha}\right)$, and the rate constants for the reaction with reduced glutathione $(\log K)$ for (meth)acrylates [11]. See Table 4 for details on each equation. ${ }^{*}$ : Tetraethyleneglycol; ${ }^{a}$ : From [10,11]; ${ }^{A}$ : From [14]; ${ }^{B}$ : Log K1 was calculated using Equation (1) derived from 11 compounds shown in obst ${ }^{\text {; }}$ C: From [6]; ${ }^{D}$ : Log K2 was calculated using Equation (2) derived from 7 compounds shown in obst ${ }^{C}$; E. From [5]; F. Log K3 was calculated using Equation (3) derived from 6 compounds shown in obst $\mathrm{E}$.

\begin{tabular}{|c|c|c|c|c|c|c|c|c|}
\hline \multirow[b]{3}{*}{ Compounds } & \multicolumn{2}{|c|}{ Chemical shifts } & \multicolumn{6}{|c|}{$\log K\left(M^{-1} s^{-1}\right)$} \\
\hline & $\mathrm{C}_{\beta}$ & $\mathrm{C}_{\alpha}$ & $\log \mathrm{K}_{1}$ & & $\log \mathrm{K}_{2}$ & & $\log K_{3}$ & \\
\hline & ppm & ppm & obsd $^{A}$ & pred $^{\mathrm{B}}$ & obsd $\mathrm{C}$ & pred $^{\mathrm{D}}$ & $\mathrm{obsd}^{\mathrm{E}}$ & $\operatorname{pred}^{F}$ \\
\hline
\end{tabular}




\begin{tabular}{|c|c|c|c|c|c|c|c|c|}
\hline MA & 130.56 & 128.15 & 1.6 & 1.0 & - & 1.1 & 1.7 & 1.9 \\
\hline EA & 130.24 & 128.59 & 1.4 & 0.9 & 1.6 & 0.9 & 1.4 & 1.8 \\
\hline $\mathrm{nBA}$ & 130.21 & 128.61 & 1.4 & 0.8 & - & 0.9 & 1.6 & 1.8 \\
\hline iBA & 130.23 & 128.60 & 1.4 & 0.9 & 1.5 & 0.9 & - & 1.8 \\
\hline $\mathrm{HA}$ & 130.23 & 128.63 & - & 0.9 & 1.3 & 0.9 & - & 1.8 \\
\hline 2-EHA & 130.17 & 128.67 & - & 0.8 & - & 0.9 & - & 1.8 \\
\hline MMA & 125.2 & 136.2 & -0.7 & -1.0 & -0.7 & -1.1 & -0.5 & -0.3 \\
\hline EMA & 124.97 & 136.51 & -0.4 & -1.1 & - & -1.2 & -0.9 & -0.4 \\
\hline iPMA & 124.95 & 136.52 & -0.9 & -1.2 & - & -1.2 & - & -0.4 \\
\hline nBMA & 124.70 & 136.41 & -0.8 & -1.2 & -0.7 & -1.3 & - & -0.6 \\
\hline iBMA & 124.98 & 136.52 & -0.6 & -1.1 & - & -1.2 & - & -0.4 \\
\hline tBMA & 124.09 & 137.96 & -0.6 & -1.5 & - & -1.5 & - & -0.8 \\
\hline HEMA & 125.89 & 135.96 & -0.3 & -0.8 & - & -0.8 & - & -0.1 \\
\hline AllyIMA & 125.46 & 136.23 & - & -1.0 & -0.3 & -0.9 & - & -0.2 \\
\hline BZMA & 125.66 & 136.21 & - & -0.9 & -0.5 & -0.9 & - & -0.1 \\
\hline EGDMA & 125.9 & 136.1 & - & -0.8 & - & -0.8 & -0.1 & 0.0 \\
\hline TEGDMA & 125.4 & 136.3 & - & -1.0 & - & -1.0 & - & 0.0 \\
\hline tetraEGDMA & - & - & - & - & - & - & 0.2 & - \\
\hline tetraEG ${ }^{*}$ & - & - & - & - & - & - & 2.2 & - \\
\hline bis-GMA & 126.2 & 135.9 & - & -0.7 & - & -0.7 & & 0.1 \\
\hline
\end{tabular}

The extent of the 13C-NMR compound movements of $\delta C_{\beta}$ and $\delta C_{\alpha}$ for (meth)acrylates was fundamentally connected with their GSH reactivity ( $\log K 1-3)(p<0.001)$. An adequate incentive for both $\delta C_{\beta}$ and $\delta C_{\alpha}$ was watched, demonstrating that GSH reactivity might be related with $\alpha, \beta$-unsaturated carboxylic esters of (meth)acrylates. As the coefficient for Equation (1), $r^{2}=0.998$, was somewhat more prominent than that for Equation (2), $\delta C_{\beta}$ esteem was utilized for foreseeing $\mathrm{K} 2$ and $\mathrm{K} 3$. The anticipated log K1-3 values for (meth)acrylates are appeared in Table 1 . The high connection coefficients propose that it was along these lines doable to anticipate the GSH reactivity with methacrylates utilizing NMR synthetic movements. Utilizing Equations (1-3), the GSH reactivity declined in the request acrylates (MA, EA, nBA, iBA, hexylA, 2ethylhexylA) $>>$ methacrylates with a useful gathering (HEMA, allyIMA, BZMA), dimethacrylates (EGDMA, TEGDMA, bisGMA)>methacrylates (MMA, EMA, iPMA, nBMA, iBMA, tBMA). Acrylates were positioned as having the most elevated GSH reactivity, subsequently plainly recommending the solid impact of the substitution design $(\mathrm{H})$ on the $\alpha$-carbon, contrasted with that $\left(\mathrm{CH}_{3}\right)$ on the $\alpha$-carbon for methacrylates (Figure 1).
${ }^{1} \mathrm{H}-\mathrm{NMR}$ concoction movements are additionally influenced by the $\beta$-electron thickness of the joined carbon. In spite of the fact that the compound move extent for ${ }^{1} \mathrm{H}-\mathrm{NMR}$ is littler than that for ${ }^{13} \mathrm{C}-\mathrm{NMR}$, assurance of the substance shifts from ${ }^{1} \mathrm{H}$ NMR could be significantly less demanding and more helpful than from ${ }^{13} \mathrm{C}$-NMR. On this introduce, QSARs utilizing the ${ }^{1} \mathrm{H}$ NMR spectra are appeared in Table 2. In Figure $1, H_{a}$ and $H_{b}$ speak to the protons trans and cis to the substituent, separately. The concoction movements of $H_{a}\left(\delta H_{a}\right)$ and $H_{b}(\delta$ $H_{b}$ ), and the move distinction amongst $H_{a}$ and $H_{b}$ for the demonstrated (meth)acrylates are appeared in Table 2, respectively. Acceptable QSARs between GSH reactivity (log K4) and $\delta H_{a}$ or $\delta H_{b}$ were watched for Equations (4-6), separately (Table 4). The relationship coefficient for $\delta \mathrm{H}_{\mathrm{a}}$ was like that for $\delta \mathrm{H}_{\mathrm{b}}$. The relationship coefficient for the move distinction amongst $\mathrm{H}_{\mathrm{a}}$ and $\mathrm{H}_{\mathrm{b}}$ was littler than that for $\delta \mathrm{H}_{\mathrm{a}}$ or $\delta$ $\mathrm{H}_{\mathrm{b}}$. The GSH reactivity ( $\left.\log \mathrm{K} 4\right)$ for the 16 monomers was anticipated utilizing Equation (4). Information are likewise appeared in Table 2.

Table $2{ }^{1} \mathrm{H}-\mathrm{NMR}$ chemical shifts $\left(\delta \mathrm{H}_{\mathrm{a}}, \delta \mathrm{H}_{\mathrm{b}}\right)$, chemical shift differences between $\delta \mathrm{H}_{\mathrm{a}}$ and $\delta \mathrm{H}_{\mathrm{b}}\left(\Delta\left|\delta \mathrm{H}_{\mathrm{a}}-\delta \mathrm{H}_{\mathrm{b}}\right|\right)$, electrophilicity $\left.\omega\right)$ and rate constants for the reaction with reduced glutathione (log K4) for (meth)acrylates [11]. ${ }^{a}$ : From [10]; ${ }^{b}:$ From [13]; ${ }^{c}$ : From [12]; d: From [6]; e: Measured in this study; ${ }^{\#}: \omega$ values calculated using DFT/B3LYP 6-31 ${ }^{*}$ in water starting from 6-31G ${ }^{*}$ geometry 
[22]. *: Calculated using Equation 14 in Table 4. ${ }^{\text {A. }}$ From [14]; ${ }^{\text {B: }}$ Calculated using Equation (4) derived from 12 compounds shown in obst A. For details on Equation (4), see Table 4.

\begin{tabular}{|c|c|c|c|c|c|c|}
\hline \multirow[b]{2}{*}{ Compounds } & \multicolumn{3}{|c|}{ NMR chemical shifts (ppm)a } & \multirow{2}{*}{$\begin{array}{l}\boldsymbol{\omega}^{\#} \\
\mathrm{eV}\end{array}$} & \multicolumn{2}{|c|}{$\log \mathrm{K} 4\left(\mathrm{~mol}^{-1} \mathrm{~min}^{-1}\right)$} \\
\hline & $\delta \mathrm{H}_{\mathrm{a}}$ & $\delta \mathrm{H}_{\mathrm{b}}$ & $\Delta\left|\delta H_{a}-\delta H_{b}\right|$ & & obsd $^{A}$ & $\operatorname{pred}^{\mathrm{B}}$ \\
\hline MA & 5.825 & 6.406 & 0.581 & 3.224 & 1.60 & 1.52 \\
\hline EA & 5.807 & 6.395 & 0.588 & 3.198 & 1.43 & 1.39 \\
\hline$n B A$ & 5.805 & 6.391 & 0.586 & 3.197 & 1.40 & 1.37 \\
\hline iBA & 5.813 & 6.400 & 0.587 & 3.196 & 1.62 & 1.45 \\
\hline HA & 5.804 & 6.391 & 0.587 & - & $1.31^{\mathrm{d}}$ & 1.36 \\
\hline 2-EHA & 5.806 & 6.385 & 0.579 & - & - & 1.40 \\
\hline MMA & 5.550 & 6.100 & 0.545 & 2.996 & -0.68 & -0.60 \\
\hline EMA & 5.541 & 6.096 & 0.555 & 2.973 & -0.40 & -0.66 \\
\hline nBMA & 5.532 & 6.091 & 0.559 & 2.959 & -0.77 & -0.75 \\
\hline iBMA & 5.543 & 6.108 & 0.565 & 2.971 & -0.63 & -0.65 \\
\hline HEMA & 5.601 & 6.149 & 0.548 & 3.011 & -0.27 & -0.20 \\
\hline AllyIMA & 5.574 & 6.138 & 0.564 & $2.994^{*}$ & $-0.29^{d}$ & -0.41 \\
\hline BZMA & 5.572 & 6.153 & 0.581 & $3.002^{*}$ & $-0.49^{d}$ & -0.42 \\
\hline TEGDMAb) & 5.56 & 6.10 & 0.54 & $2.990^{*}$ & - & -0.52 \\
\hline bis-GMAb) & 5.56 & 6.10 & 0.54 & $3.025^{*}$ & - & -0.52 \\
\hline bis-GMAc) & 5.60 & 6.14 & 0.54 & - & - & -0.21 \\
\hline TEGDMAe) & 5.56 & 6.13 & 0.57 & - & - & - \\
\hline
\end{tabular}

The anticipated log $\mathrm{K} 4$ values for (meth)acrylates were appeared to decrease in the request acrylates (MAA, EAA, nBMA, iBAA, 2-ethylhexylA) > methacrylates with a useful gathering (HEMA, AllyIMA, BZMA), dimethacrylates (EGDMA, UDMA, bis-GMA)>methacrylates (MMA, EMA, nBMA, nBMA, iBMA). The request of reactivity was like that got utilizing ${ }^{13} \mathrm{C}$ NMR spectra.

\section{Relation between acute toxicity and GSH reactivity}

The instrument of detoxication of acrylates and methacrylates includes conjugation with GSH. GSH reactivity has been accounted for as a reason for poisonous quality $[5,6]$. Utilizing five acrylates and five methacrylates, we explored the connections between $\mathrm{LD}_{50}$ in mice and GSH reactivity (log K1 and K4). The intense danger of the (meth)acrylates for ICR mice was around 10-overlap more prominent than that for ddY mice. This huge uniqueness may be by the diverse harmfulness testing strategies utilized in this review: the $L_{50}$ values in ICR mice were gotten by intraperitoneal infusion lethality test, though it was by oral organization test for $\mathrm{ddY}$ mice. On the distinctive poisonous quality testing techniques utilized, a straight connection between the toxicities was watched. Table 4 demonstrates the QSARS between GSH reactivity (log K1, log $\mathrm{K} 4)$ and intense poisonous quality $\left(\mathrm{LD}_{50}\right)$ in mice. Aside from HEMA, the intraperitoneal LD50 esteem in ICR mice were exceedingly corresponded with log $\mathrm{K} 1$ or $\log \mathrm{K} 4\left(\mathrm{r}^{2} \approx 0.8\right.$, $\mathrm{p}<0.01)$. Interestingly, the oral LD50 values in ddY mice were seen with a poor relationship $\left(n=9, r^{2}=0.457, p<0.05\right)$. Likewise, there was a huge straight connection between the LD50 (in ICR mice or ddY mice) and log K (K1 or K4) for the (meth)acrylates. An adequate coefficient for K1 was seen between the two arrangements of the $\mathrm{LD}_{50}$ esteem (intraperitoneal versus oral) yet with poor relationship $\left(r^{2}=0.5\right.$, $\mathrm{p}<0.05$ ) in both ICR mice and ddY mice. A decent coefficient for K1 was watched when HEMA was expelled (Equations 8-12). The intense poisonous quality in mice for (meth)acrylates was identified with their GSH reactivity; that for $d d Y$ mice demonstrated a more adequate QSAR regarding both log $\mathrm{K} 1$ and $\log \mathrm{P}$ than that in each term (Equation 13). The $L D_{50}$ values for the (meth)acrylates dictated by Equation 13 are appeared in Table 3. Additionally, the anticipated $L D_{50}$ values in mice for EA, MMA, nBMA, BZMA, AllyIMA, TEGDMA and bis-GMA are contrasted with those revealed in the writing for rats by means of the oral course (Table 3 ). The oral $L_{50}$ values for the monomers EA, MMA and TEGDMA in mice were like those in rats (Table 3 ). Be that as it may, the anticipated oral $L_{50}$ values for allyIMA and bis-GMA in rats were around 20-crease more prominent than those in mice. Thus, the oral $\mathrm{LD}_{50}$ values for $\mathrm{nBMA}$ and BZMA in rats were around 4-overlay more prominent than those in mice. The lethality of allyIMA and bis-GMA might be identified with their hydrolysis items notwithstanding the distinction in the creature species and 
danger test strategies utilized. The $L_{50}$ in mice of (met)acrylates was modestly associated to their log P $[13,14]$. We found that anticipated log $K$ esteem was respectably associated to Invivo $\mathrm{LD}_{50}$ esteem when HEMA was expelled. The poisonous quality of the water solvent HEMA $(\log \mathrm{P}=0.47$, Invivo $\mathrm{LD}_{50}$ in mice $=45.24 \mathrm{~m} \mathrm{~mol} / \mathrm{kg}$, separately) was more noteworthy than that of the water less dissolvable EMA (log $\mathrm{P}=1.94, \quad L D_{50}$ in mice=68.64 $\mathrm{m} \mathrm{mol} / \mathrm{kg}$, individually). Interestingly, the $\delta C_{\beta}$ esteem (ppm) of HEMA has 125.89 and that of EMA has 124.97, bringing about the way that log $\mathrm{K}$ of HEMA (-0.3) was somewhat yet altogether more prominent than EMA's one (-0.4). On the comparative introduce, a causal connection between Invivo $\mathrm{LD}_{50}$ in mice and or log $\mathrm{k}$ esteem for 2-hydroxyethyl acrylate (2HEA) and ethyl acrylate (EA). This was proven by looking at the individual information for $2 \mathrm{HEA}$ $(\log \mathrm{P}=-0.21$, esteem $=3.214 \mathrm{eV}$, separately) to $\mathrm{EA}(\log \mathrm{P}=1.33$, esteem=3.1981 eV, individually); i.e., both have for all intents and purposes comparable values, yet altogether unique response rates ( $\log k=1.92$ versus 1.43 , individually) and dangerous potencies $\left(\mathrm{LD}_{50}=5.2 \mathrm{~m} \mathrm{~mol} / \mathrm{kg}\right.$ versus $18 \mathrm{~m} \mathrm{~mol} / \mathrm{kg}$, separately) [23]. Take note of that the $\delta C_{\beta}$ estimation of $2 \mathrm{HEA}$ is $130.4 \mathrm{ppm}$, though EA is $130.24 \mathrm{ppm}$. Albeit both mixes demonstrated essentially comparative pei-thickness and values, the dangerous intensity of 2HEA and HEMA was more noteworthy than that of relating EA and EMA. Consequently, the colossal poisonous potencies of 2HEA and HEMA might be identified with $\mathrm{OH}$ gatherings of these mixes.

Table 3 The observed and predicted values for 50 lethal dose $\left(L D_{50}\right)$, and log $P$ (octanol-water partition coefficient) for (meth)acrylates [11] A: Predicted using Equation (9) derived from the observed values (Obsd) for 9 compounds except HEMA; ${ }^{B}$ : Predicted using Equation (13) derived from the observed value for 8 compounds except HEMA; ${ }^{\text {a: }}$ From [14]; b: From [15]; c:

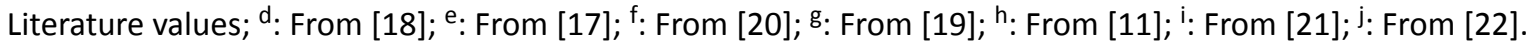

\begin{tabular}{|c|c|c|c|c|c|c|}
\hline \multirow[b]{3}{*}{ Compounds } & \multirow[b]{3}{*}{$\log P^{a}$} & \multirow{2}{*}{\multicolumn{2}{|c|}{$\frac{\mathrm{LD}_{50} \mathrm{~b}}{\text { Intraperitoneal ICR mice }}$}} & \multicolumn{2}{|c|}{$\mathrm{LD}_{50}{ }^{\mathrm{a}}$} & \multirow[b]{3}{*}{$\begin{array}{l}\text { Oral rat } L D_{50}{ }^{\circ} \\
\mathrm{mmol} / \mathrm{kg}\end{array}$} \\
\hline & & & & Oral ddY & & \\
\hline & & $\begin{array}{l}\text { Obsd } \\
\mathrm{mmol} / \mathrm{kg}\end{array}$ & $\begin{array}{l}\text { Pred }^{\mathrm{A}} \\
\mathrm{mmol} / \mathrm{kg}\end{array}$ & $\begin{array}{l}\text { Obsd } \\
\mathrm{mmol} / \mathrm{kg}\end{array}$ & $\begin{array}{l}\text { Pred }^{\mathrm{B}} \\
\mathrm{mmol} / \mathrm{kg}\end{array}$ & \\
\hline MA & 0.80 & 2.95 & 5.5 & 9.60 & 29.4 & - \\
\hline EA & 1.33 & 5.99 & 5.8 & 17.97 & 51.4 & $<50^{\mathrm{e}}$ \\
\hline$n B A$ & 2.36 & 6.65 & 5.8 & 58.98 & 85.5 & - \\
\hline iBA & 2.22 & 5.93 & 5.7 & 47.63 & 85.1 & - \\
\hline 2-EHA & $3.72^{\mathrm{b}}$ & 7.20 & 5.8 & - & - & - \\
\hline MMA & 1.38 & 11.22 & 10.3 & 51.97 & 69.4 & $79^{d}$ \\
\hline EMA & 1.94 & 10.90 & 10.4 & 68.64 & 107.3 & - \\
\hline nBMA & 2.88 & 10.48 & 10.6 & 142.70 & 144.6 & $113^{f}$ \\
\hline iBMA & 2.66 & 8.94 & 10.4 & 83.14 & 134.6 & - \\
\hline HEMA & 0.47 & 4.06 & 9.4 & 45.24 & - & - \\
\hline AllyIMA & 1.57 & - & 9.8 & - & 90.3 & - \\
\hline BZMA & 2.53 & - & 9.9 & - & 125.4 & - \\
\hline TEGDMA & $1.55^{\mathrm{h}}$ & - & 11.2 & - & 89.7 & - \\
\hline bis-GMA & $5.07^{\mathrm{h}}$ & - & 10.1 & - & 218.2 & - \\
\hline
\end{tabular}

According to the Frontier Orbital Theory, adduct formation occurs when a soft nucleophile such as GSH donates its highest energy electrons into the empty lowest energy orbital (LUMO) of a soft electrophiles such as (meth)acrylates. Therefore, the most relevant frontier orbital for electrophiles is the LUMO (Lowest Unoccupied Molecular Orbital), whereas the HOMO (Highest Occupied Molecular Orbital) is most important for nucleophiles. HOMO and LUMO energy are broadly used as indicator variables of molecular electron donor or acceptor affinity, which should represent the electrophilicity or nucleophilicity of a compound to a certain extent [24-26]. In biological system, proteins with $\mathrm{SH}$ and $\mathrm{NH}_{2}$ groups act as nucleophiles. The electrophilicity index $(\omega)$ of monomers was calculated as $\omega=2 / 2$, where electronegativity ( $\chi$ was calculated as $\left.=-\left(\mathrm{E}_{\mathrm{LUMO}}+\mathrm{E}_{\mathrm{HOMO}}\right)\right)$ and chemical hardness $(\eta)$ was calculated as $\left.\eta=E_{L U M O}-E_{\text {HOMO }}\right) / 2$, respectively $[18,24-26]$. The $\omega$ esteem has been identified as the best descriptor for the electrophilicity of $\alpha$ and $\beta$ unsaturated carbonyl compounds $[27,28]$. 
Toxic intermediates of monomers in different metabolic transformations

Responsive oxygen species (ROS), including nitrogen oxide are created Invivo by different procedures, frequently as harmful intermediates in various metabolic changes, and potential lethal metabolites coming about because of hydroxylation of twofold bonds and sweet-smelling frameworks in vinyl monomers have been appeared to assume a critical part for countless and sicknesses. GSH reactivity for acrylates, methacrylates and dimethacrylates was altogether identified with the extent of NMR substance movements of $\beta$ carbon. The substance move go for ${ }^{1} \mathrm{H}-\mathrm{NMR}$ was littler than that for ${ }^{13} \mathrm{C}$ NMR. In this manner, it would be more appropriate to utilize ${ }^{13} \mathrm{C}-\mathrm{NMR}$ as a determinant of the $\mathrm{GSH}$ reactivity of monomers. The rank request of GSH reactivity was acrylates > methacrylates with a practical gathering; hydroxyl, benzyl or allyl constituent $\approx$ dimethacrylates>methacrylates with a short-chain aliphatic substituent. Dynamic acrylates, for example, 2HEA, MA, EA and iBA were already answered to demonstrate notably more prominent poisonous quality in fathead minnow or mice than methacrylates, for example, MMA $[6,17]$. Acrylates with a high GSH reactivity indicate higher lethality than methacrylates with a low GSH reactivity $[6,23]$. Then again, in spite of the fact that allyIMA indicates bring down GSH reactivity than the acrylates EA and iBA, AllyMA demonstrated more noteworthy lethality than the last [22]. This was beforehand answered to be because of a result of allyl liquor gotten from hydrolysis of this monomer; a responsive acroline delivered by liquor dehydrogenase in liver [24]. In the present review, the anticipated $L_{50}$ for allyIMA was like that for $\mathrm{BA}$, proposing that the solid danger of allyMA in creature tests might be identified with its hydrolysis items. The Invivo harmfulness got utilizing mice intraperitoneally infused with the monomer HEMA bearing a hydroxyl substituent was higher than that for nBA and iBA [13], recommending a conceivable connection between $\log K$ of cysteine adduct development and the statement of Invivo lethality. In another idea, this might be because of ethylene glycol, a result of HEMA hydrolysis. Ethylene glycol is processed from HEMA through liquor dehydrogenase to glycolaldehyde, which is then quickly utilized to glycolate. Ethylene glycol harmfulness is mind boggling and not completely saw, but rather due for the most part to extreme metabolic acidosis brought on by glycolate [25]. These discoveries recommend that the danger of some methacrylate monomers might be affected by hydrolysis as well as metabolic items gotten from the first parent monomers. The generally high intense poisonous quality of ethylenglycol dimethacrylate (EGDMA) $\left(\mathrm{LD}_{50}\right.$ in mice by means of the oral course, around $10 \mathrm{mmol} / \mathrm{kg}$ [26]) might be identified with hydrolysis items, methacrylic corrosive, HEMA and ethylene glycol gotten from the first EGDMA. Additionally, the GSH reactivity of BZMA, a fragrant methacrylate, was more prominent than that of the aliphatic methacrylates. A liquor moiety, benzyl liquor, gotten from BZMA hydrolysis, was accounted for to be of toxicological significance since benzyl alcohols may show poisonous quality by means of a radical instrument [27]. In the present review, the anticipated $L D_{50}$ for
BZMA was like that for BMA. The contrast between the anticipated and test information for BZMA might be because of BZMA hydrolysis, in light of the fact that the danger of this compound anticipated utilizing QSAR did not consider its hydrolysis items. The GSH reactivity for the dimethacrylates, EGDMA and TEGDMA, was like that for HEMA. TEGDMA lessens intracellular GSH levels and influences cell digestion at various levels $[9,28]$. It is outstanding that triethylene glycol and methacrylic corrosive are results of TEGDMA hydrolysis. Triethylene glycol delivered by TEGDMA hydrolysis might be identified with GSH reactivity. Tetraethylene glycol demonstrates notably higher GSH reactivity than tetraethyleneglycol dimethacrylate (TetraEGDMA) [5] (see Table 1). This recommends the ethylene glycol oligomers, diethylene glycol, triethylene glycol and tetraethylene glycol, gotten from comparing dimethacrylate hydrolysis may play a substantially more essential part in intense danger than the first dimethacrylates bearing ethylene glycol gatherings. Then again, a few examinations have announced that bis-GMA (the expansion result of methacrylic corrosive and bisphenol Adiglycidyl ether) is deteriorated by enzymatic or concoction hydrolysis, yielding the mixes [29,30]: methacrylic corrosive, (2-[4-(2,3-dihydroxypropoxy) phenyl]-2-[4-(2-hydroxy-3methacryloxypropox) phenyl] propane), 2,2'- bis[4-(2,3dihydroxypropoxy)phenyl]propane (BHP) and 2-(4hydroxyphenyl)- 2-[4-(2,3-dihydroxypropoxy)phenyl]propane. The anticipated intense lethality of bis-GMA was low (218 $\mathrm{mmol} / \mathrm{kg}$ ) (Table 3). In any case, creature testing by means of intraperitoneal infusion yielded a generally high lethality of bis-GMA (around $10 \mathrm{mmol} / \mathrm{kg}$ [22]. Along these lines, while it was accounted for on one hand that apoptosis or cell passing was actuated by the metabolic oxidation of a solitary terminal hydroxy gathering of the parent glycol [2], the generally high poisonous quality of bis-GMA was provably credited to its hydrolytic metabolites.

\section{NMR chemical shift of $\beta$-carbon and electrophilicity}

The ${ }^{13} \mathrm{C}$-NMR compound move of the $\beta$-carbon $\left(\delta C_{\beta}\right)$ of monomers is additionally quantitatively identified with the $\pi$ electron thickness of $\beta$-carbons. Along these lines, it is sensible to connect the extent of the $\delta$ of $\beta$-carbon with the reactivity of monomers. The rank request of the $\delta$ estimation of $\beta$ carbon was acrylates>dimethacrylates (EGDMA, TEGDMA, bisGMA)>methacrylates. The rank of $\delta C_{\beta}$ value in dental monomers declined in the request HEMA, EGDMA $>T E G D M A>M M A$. In view of recurrence of positive tests and ability to instigate wide cross-reactivity in guinea pigs, HEMA to be the most clinically pertinent methacrylate contact sensitizer [31]. ${ }^{13} \mathrm{C}$ NMR move investigation of the $\alpha$ and $\beta$ carbons of the twofold bond $(C=C)$ could catch the quality of its Michael-tolerating abilities. For monomethacrylates, the action of HEMA might be identified with its moderately high $\delta C_{\beta}$ value. Chan and O'Brien detailed that the non-enzymic thiol reactivity (KGSH) of acrylates (MA, 2-HEA, EA, isobutyl A, hexylA) and methacrylates (MMA, EMA, Allyl MA, 2-hydroxypropyl MA, iBMA) is straightly identified with their fractional charge of $\beta$-carbon computed $\left(r^{2}=0.94\right.$, 
$\mathrm{p}<0.001)$ utilizing the CAChe MOPAC quantum repairman application [32]. Furthermore, they announced that Invivo $\mathrm{LD}_{50}$ in rodent for ten acrylates and methacrylates was be tolerably related to the Invitro $\mathrm{LC}_{50}$ esteem for hepatocytes $\left(r^{2}=0.65, P<0.05\right)$. In any case, no noteworthy connections were found between the Invivo $\mathrm{LD}_{50}$ in rodent esteem and $\mathrm{GSH}$ reactivity or the physico-synthetic parameters, for example, fractional charges of $\beta$-carbon and $\alpha$-carbon, and LUMO vitality [32]. Also, no connections were seen between Invivo danger and $\log \mathrm{P}$. The Invivo poisonous quality might be dictated by complex mix of components, related toxicokinetics. In light of the discoveries of the present review, worthy connections were found for the NMR compound movements $\left(\delta \mathrm{C}_{\beta}\right.$ and $\delta \mathrm{H}_{\mathrm{a}}$ ) and GSH reactivity (log K) or the electrophilicity ( $\omega$ value appeared in Equations 14 and 15. These discoveries emphatically proposed that (meth)acrylates may shape adducts with cysteine and other amino corrosive focuses on proteins through second request (covalent) responses [33]. MMA-incited exhaustion of GSH and oxidized glutathione (GSSG) in rodent liver and kidney has been accounted for [31]. In this review, the likelihood of causable connections between intense harmfulness and the GSH reactivity (log $\mathrm{K}$ ) of (meth)acrylates may be identified with Invivo GSH, and GSSG depletion [5,6,14,32].

(Meth)acrylates with potential Michael acceptor capacity can prompt undesirable symptoms, for example, cell-harm, cytotoxicity or mutagenecity. (Meth)acrylates with $\alpha$, $\beta$ unsaturated carbonyl gatherings, electrophiles might be specially assaulted by nucleophiles (water, hydroxyl anion $\left(\mathrm{OH}^{-}\right), \mathrm{NO}$, glutathione (GSH), thiyl radical (GS-) [6]. An anion; that is, a particle with a negative electrical charge could add to the $\mathrm{C}_{\beta}$ of monomers and furthermore $\mathrm{GSH}$ and $\mathrm{N}$ acetylcysteine (NAC) could conjugate monomers. That the $\alpha$, $\beta$-unsaturated carbonyl mixes like (meth)acrylate monomers go about as radical foragers, for instance, by thiol catching [34]. (Meth)acrylate-initiated carcinogenesis might be obstructed by an assortment of substances that can incite (actuate) certain catalysts, for instance, quinone reductase and glutathione S-transferase action, which then restrains the receptive electrophilic types of cancer-causing agents [34]. The mammalian cell quality change test (MCGM) test yet in spite of the fact that the genotoxic capability of the substances are not applicable for man, the genotoxic strength is thought to be because of atomic reactivity [35]. Numerous concoction toxicants like MA and EA, dynamic acrylates and TEGDMA with two Michael-response acceptor [36] demonstrated generally expansive $\delta C_{\beta}$ values. MCGM positive substances are included in the irreversible response of toxicant (or vinyl monomers) and their dynamic metabolites are electrophiles that cause cell damage by framing covalent bonds with nucleophilic focuses on organic macromolecules, for example, proteins and DNA [4]. Computational estimation strategy might be helpful to illuminate the poisonous quality and sensitivity instrument of (meth)acrylates [32,37-39]. Especially, acrylates with the high $\delta C_{\beta}$ esteem demonstrated the colossal $\omega$ esteem (Equations 14, 15 in Table 4; the $\omega$ esteem [38]). A decent direct connection between $\delta \mathrm{C}_{\beta}$ or $\delta \mathrm{H}_{\mathrm{b}}$ and $\omega$ esteem for (meth)acrylates (Equations 14, and 15) was watched $\left(r^{2}=0.99\right.$, $\mathrm{p}<0.001$ ) (Table 4). Also, the ${ }^{13} \mathrm{C}$ NMR chemical shift of $\beta$ carbon for $\alpha, \beta$-unsaturated carboxylic esters of methacrylate monomers might provide a closer insight in clarifying the mechanism of monomer-induced cytotoxicity. TEGDMA, DEGDMA and bis-GMA with two Michael reaction aceptor and HEMA, monomethacrylate with $\mathrm{OH}$ group are more cytotoxic via apoptosis than MMA, monomethacrylate without functional groups $[2,37]$. These cytotoxic monomers enhance the formation of reactive oxygen species (ROS) $[4,39]$ and elicit cyclooxygenase 2 (Cox-2), nitric oxide synthase 2 (Nos2) and TNF- $\alpha$ gene and protein expression for RAW 264.7 cells which are most likely the cause of biological reactions activated by dental composites and resin monomers. The pro-inflammatory activity of monomers like TEGDMA and HEMA may be associated with their higher $\delta C_{\beta}$ and GSH reactivity value.

At the end of the day, the NMR synthetic movements of $\alpha, \beta$ unsaturated carboxylic esters of methacrylate monomers could be utilized as a way to quantify and foresee their intense poisonous quality notwithstanding the log P-term and also as way to estimate cytotoxic mechanisms.

Table 4 Quantitative structure-activity relationships (QSARs) between: (A) GSH reactivity (log K1, K2, K3, or K4) and NMRchemical shifts $\left(\delta_{\beta}, \delta H_{a}, \delta H_{b}\right.$ or $\left.\Delta\left|\delta H_{a}-\delta H_{b}\right|\right)$; (B) between $L_{50}(50 \%$ lethal dose) and descriptors (log K1, log K4, log P) and (C) between $\delta C_{\beta}$ or $\delta H_{a}$ and $\omega$ value. For descriptors see Tables 1-3, respectively. For $\omega$ value see Table 2.

\begin{tabular}{|l|l|}
\hline A) & Equation (1) \\
\hline $\log \mathrm{K}_{1}=-48.6( \pm 0.2)+0.4( \pm 0.0) \delta C \beta\left(n=11, \mathrm{r}^{2}=0.998, p<0.001\right)$ & Equation (2) \\
\hline $\log \mathrm{K}_{2}=-51.2( \pm 0.1)+04( \pm 0.0) \delta \mathrm{C} \beta\left(\mathrm{n}=7, \mathrm{r}^{2}=0.99, \mathrm{p}<0.001\right)$ & Equation (3) \\
\hline $\log \mathrm{K}_{3}=-52.9( \pm 0.2)+04( \pm 0.0) \delta \mathrm{C} \beta\left(\mathrm{n}=6, \mathrm{r}^{2}=0.85, \mathrm{p}<0.001\right)$ & Equation (4) \\
\hline $\log \mathrm{K}_{4}=-43.5( \pm 0.1)+7.7( \pm 0.3) \delta \mathrm{Ha}\left(\mathrm{n}=12, \mathrm{r}^{2}=0.99, \mathrm{p}<0.001\right)$ & Equation (5) \\
\hline $\log \mathrm{K}_{4}=-27.5( \pm 0.6)+48.6( \pm 12.5)|\delta \mathrm{Ha}-\delta \mathrm{Hb}|\left(n=12, \mathrm{r}^{2}=0.63, \mathrm{p}<0.01\right)$ & \\
\hline $\mathrm{B})$ & Equation $(6)$ \\
\hline $\mathrm{LD}_{50}{ }^{*}=9.1( \pm 2.2)-1.9( \pm 0.7) \log \mathrm{K} 1\left(n=10, \mathrm{r}^{2}=0.48, p<0.05\right)$ & Equation $(7)$ \\
\hline $\mathrm{LD}_{50}{ }^{*}=9.9( \pm 2.1)-1.7( \pm 0.7) \log \mathrm{K} 4\left(\mathrm{n}=10, \mathrm{r}^{2}=0.48, p<0.05\right)$ & \\
\hline
\end{tabular}




\begin{tabular}{|l|l|}
\hline$L D_{50}{ }^{*}=10.4( \pm 1.3)-2.2( \pm 0.5) \log K 1$ (outlier: HEMA, $\left.n=9, r^{2}=0.80, p<0.01\right)$ & Equation (8) \\
\hline$L D_{50}{ }^{*}=8.9( \pm 2.1)-2.3( \pm 0.7) \log K 4$ (outlier: HEMA, $\left.n=9, r^{2}=0.8, p<0.01\right)$ & Equation (9) \\
\hline$L D_{50}{ }^{\#}=60( \pm 30.9)-27.7( \pm 10.6) \log K 1$ (outlier: HEMA, $\left.n=8, r^{2}=0.52, p<0.05\right)$ & Equation (10) \\
\hline$L D_{50}{ }^{\#}=-4.8( \pm 27.1)+435.5( \pm 11.5) \log P\left(n=9, r^{2}=0.58, p<0.05\right)$ & Equation (11) \\
\hline$L D_{50}{ }^{\#}=70.2( \pm 31.4)-26.1( \pm 10.6) \log K 4\left(\right.$ outlier: $\left.H E M A, n=8, r^{2}=0.55, p<0.05\right)$ & Equation (12) \\
\hline$L D_{50}{ }^{\#}=15.1( \pm 17.3)+37.9( \pm 10.1) \log P-16.4( \pm 6.7) \log K 1$ & Equation (13) \\
\hline$\left(\right.$ outlier: $\left.H E M A, n=8, r^{2}=0.88, p<0.01\right)$ & \\
\hline$C)$ & Equation (14) \\
\hline$\delta C b=55.74( \pm 0.19)+23.29( \pm 0.50) \omega\left(n=9, r^{2}=0.997, p<0.001\right)$ & Equation (15) \\
\hline$\delta H a=2.14( \pm 0.03)+1.14( \pm 0.10) \omega\left(n=9, r^{2}=0.950, p<0.001\right)$ & \\
\hline
\end{tabular}

\section{Conclusions}

In light of distributed information for the GSH reactivity, intense lethality and NMR spectra of (meth)acrylates, QSAR studies were done. GSH reactivity for (meth)acrylates was fundamentally identified with their ${ }^{13} \mathrm{C}-\mathrm{NMR}$ spectra $\delta \mathrm{C}_{\beta}$ ) and ${ }^{1} \mathrm{H}$-NMR spectra $\left(\delta \mathrm{H}_{\mathrm{a}}\right.$ and $\left.\delta \mathrm{H}_{\mathrm{b}}\right)$. NMR spectra for (meth)acrylates in dentistry can be utilized to anticipate their poisonous quality on the grounds that there is an adequate connection between GSH reactivity and intense danger. Notwithstanding, metabolic changes of the first monomers may influence Invivo lethality. The present findings strongly suggested that acrylates $\left(\mathrm{CH}_{2}=\mathrm{CH}-\mathrm{COOR}\right)$ should not be used as the dental bulk-fill resin system because their high Michael acceptor function. Acrylates can preferably lead to unwanted side effects, such as cell-damage, cytotoxicity, allergic contact dermatitis or mutagenicity. Despite the finding that dental resin components have been improved their physico-chemical properties [40], the concerns for their intrinsic toxicity remains to be established. ${ }^{13} \mathrm{C}-\mathrm{NMR}$ chemical shift analysis of the $\alpha$ and $\beta$ carbon of the double bond captures the strength of its Michael-accepting capability. At the end of the day, the NMR synthetic movements of $\alpha, \beta$-unsaturated carboxylic esters of methacrylate monomers could be utilized as a way to quantify and foresee their intense poisonous quality notwithstanding the log P-term.

\section{References}

1. Vankerckhoven $\mathrm{H}$, Lambrechts $\mathrm{P}$, van Beylen $\mathrm{M}$, Davidson $\mathrm{CL}$, Vanherle G (1982) Unreacted methacrylate groups on the surfaces of composite resins. J Dent Res 61: 791-795.

2. Schweikl H, Spagnuolo G, Schmalz G (2006) Genetic and cellular toxicology of dental resin monomers. J Dent Res 85: 870-877.

3. Aalto-Korte K, Alanko K, Kuuliala O, Jolanki R (2007) Methacrylate and acrylate allergy in dental personnel. Contact Dermatitis 57: 324-330.

4. Goldbrrg M (2008) In vitro and invivo studies on the toxicity of dental resin components: A review. Clin Oral Invests 12: 1-8.

5. McCarthy TJ, Hayes EP, Schwartz CS, Witz G (1994) The Reactivity of selected acrylate esters toward glutathione and deoxyribonucleosides in vitro: Structure-activity relationships. Fundam Appl Toxicol 22: 543-548.

6. Freidig AP, Verhaar HJM, Hermens JLM (1999) Quantitative structure-property relationships for the chemical reactivity of acrylates and methacrylates. Environ Toxicol Chem 18: 1133-1139.

7. Yarbrough JW, Schultz TW (2007) A biotic sulfhydryl reactivity: a predictor of aquatic toxicity for carbonyl-containing alpha, betaunsaturated compounds. Chem Res Toxicol 20: 558-562.

8. Ahlfors SR, Sterner O, Hansson C (2003) Reactivity of contact allergenic haptens to amino acid residues in a model carrier peptide and characterization of formed peptide-hapten adducts. Skin Pharmacol Appl Skin Physiol 16: 59-68.

9. Volk J, Engelmann J, Leyhausen G, Geurtsen W (2006) Effects of three resin monomers on the cellular glutathione concentration of cultured human gingival fibroblasts. Dent Mater 22: 499-505.

10. Hatada K, Kitayama T, Nishiura T, Shibuya W (2002) Relation between reactivities of vinyl monomers and their NMR spectra. Current Org Chem 6: 121-153.

11. Fujisawa S, Kadoma Y (2009) Prediction of the reduced glutathione $(\mathrm{GSH})$ reactivity of dental methacrylate monomers using NMR spectra-Relationship between toxicity and GSH reactivity. Dent Mater J 28: 722-729.

12. Fujisawa $S$ (1994) Nuclear magnetic resonance spectra of BisGMA and Iso-bis-GMA. Dent Mater J 13: 251-255.

13. Lawrence WH, Bass GE, Purcell WP, Autian J (1972) Use of mathematical models in the study of structure-toxicity relationships of dental compounds. I. Esters of acrylic and methacrylic acids. J Dent Res 51: 526-535.

14. Tanii H, Hashimoto K (1982) Structure-toxicity relationship of acrylates and methacrylates. Toxicol Lett 1: 125-129.

15. Vankerckhoven $\mathrm{H}$, Lambrechts $\mathrm{P}$, van Beylen $\mathrm{M}$, Vanherle $\mathrm{G}$ (1981) Characterization of composite resins by NMR and TEM. J Dent Res 60: 1957-1965.

16. Weil CS (1952) Tables for convenient calculation of median effective dose (LD50 or ED50) and instructions in their use. Biometrics 8: 249-263.

17. Material Safety Data Sheet (2007) Alkemia Canada Inc.

18. Material Safety Data Sheet (2001) Flexbar Machine Co. NY.

19. Material Safety Data Sheet (2005) Physical and Theoretical Chemistry Lab, Oxford University. 
20. Material Safety Data Sheet (2006) ProSciTech, Australia.

21. Material Safety Data Sheet (1995) Sigma-Aldrich, Germany.

22. Material Safety Data Sheet (2004) Ivoclar Vivadent, USA.

23. Karabunarliev S, Mekenyan OG, Karcher W, Russom CL, Steven P (1996) Quantum-chemical descriptors for estimating the acute toxicity of electrophiles to the fathed minnow (pimephales promelas): An analysis based on molecular mechanisms. QuantStruct-Act Relat 15: 302-310.

24. Ohno Y, Jones TW, Ormstad K (1985) Allyl alcohol toxicity in isolated renal epithelial cells: protective effects of low molecular weight thiols. Chem Biol Interact 52: 289-299.

25. Jacobsen D, McMartin KE (1986) Methanol and ethylene glycol poisonings. Mechanism of toxicity, clinical course, diagnosis and treatment. Med Toxicol 1: 309-334.

26. US National Library of Medicine (2008).

27. Kapur S, Shusterman A, Verma RP, Hansch C, Selassi CD (2000) Toxicology of benzyl alcohols: a QSAR analysis. Chemosphere 41: 1643-1649.

28. Engelmann J, Leyhausen G, Leibfritz D, Geurtsen W (2001) Metabolic effects of dental resin components in vitro detected by NMR spectroscopy. J Dent Res 80: 869-875.

29. Kostoryz EL, Eick JD, Glaros AG, Judy BM, Welshons WV, et al. (2003) Biocompatibility of hydroxylated metabolites of BISGMA and BFDGE. J Dent Res 82: 367-371.

30. Kadoma Y, Tanaka M (2000) Acid and base-catalyzed hydrolysis of bisphenol A-related compounds. Dent Mater J 19: 139-152.

31. Rustemeyer T, de Groot J, von Blomberg BM, Frosch PJ, Scheper RJ (1998) Cross-reactivity patterns of contact-sensitizing methacrylates. Toxicol Appl Pharmacol 148: 83-90.
32. Chan K, O'Brien PJ (2008) Structure-activity relationships for hepatocyte toxicity and electrophilic reactivity of alpha,betaunsaturated esters, acrylates and methacrylates. J Appl Toxicol 28: 1004-1015.

33. Rodrigues T, Reker D, Schneider P, Schneider G (2016) Counting on natural products for drug design. Nature Chemistry 8: 531-541.

34. Broschinski L, Madle S, Hensel C (1998) Genotoxicity tests for new chemicals in Germany: routine in vitro test systems. Mutat Res 418: 121-129.

35. Pérez-Garrido A, Helguera AM, Rodríguez FG, Cordeiro $M N$ (2010) QSAR models to predict mutagenicity of acrylates, methacrylates and alpha,beta-unsaturated carbonyl compounds. Dent Mater 26: 397-415.

36. Ishihara M, Fujisawa S (2009) A sructure-activity relationship study on the mechanisms of methacrylate-induced toxicity using NMR chemical shift of ?-carbon, RP-HPLC log $P$ and semiimpirical molecular descriptor. Dent Mater J 28: 113-120.

37. Lopachin RM, Gavin T, Decaprio A, Barber DS (2012) Application of the hard and soft, acids and bases (HSAB) theory to toxicanttarget interaction Chem. Res Toxicol 25: 239-251.

38. Enoch ST, Cronin MTD, Schulz TW, Madden JC (2008) Quantitative and mechanistic read across for predicting the skin sensitization potential of alkenes acting via Michael addition. Chem Res Toxicol 21: 513-520.

39. Krifka S, Spagnuolo G, Schmalz G, Schweikl H (2013) A review of adaptive mechanisms in cell responses towards oxidative stress caused by dental resin monomers. Biomaterials 34: 4555-4563.

40. Cramer NB, Stansbury JW, Bowman CN (2011) Recent advances and developments in composite dental restorative materials. Dent Res 90: 402-416. 